\title{
Masticatory Efficiency in Denture Wearers with Bilateral Balanced Occlusion and Canine Guidance
}

\author{
Arcelino FARIAS NETO ${ }^{1}$ \\ Wilson MESTRINER JUNIOR ${ }^{2}$ \\ Adriana da Fonte Porto CARREIRO²
}

\begin{abstract}
${ }^{1}$ Piracicaba Dental School, State Univeristy of Campinas, Piracicaba, SP, Brazil
${ }^{2}$ Ribeirão Preto Dental School, University of São Paulo, Ribeirão Preto, SP, Brazil

${ }^{2}$ Dental School, Rio Grande do Norte Federal University, Natal, Brazil
\end{abstract}

\begin{abstract}
The maintenance of masticatory function is especially important for patients wearing complete dentures due to their limitations. Thus, the bilateral balanced occlusal concept is used to achieve greater masticatory efficiency. However, a critical review of the literature reveals that there is not sufficient scientific evidence to support bilateral balanced occlusion as the most appropriate occlusal concept in complete dentures. Therefore, the aim of this study was to evaluate the masticatory efficiency in complete dentures wearers with bilateral balanced occlusion and canine guidance. A double-blinded controlled crossover clinical trial was conducted. The sample was composed by 24 edentulous patients who wore sets of complete dentures with both occlusal concepts during equal periods of 3 months. Objective data were collected through the masticatory efficiency test performed by the colorimetric method with the beads, in which capsules of a synthetic material enclosing fuchsine-containing granules were used. Subjective data were recorded by patient's ratings of their chewing function. No significant statistical difference was found for masticatory efficiency $(p=0.095)$ between the two occlusal concepts studied. The results suggest that bilateral balanced occlusion does not improve the masticatory efficiency in complete denture wearers.
\end{abstract}

Key Words: balanced occlusion, canine guidance, complete dentures, masticatory efficiency, edentulousness.

\section{INTRODUCTION}

The treatment with complete dentures (CD) aims to restore patient's masticatory function and speaking ability, leading to a better facial appearance and social living. The appropriate masticatory function is of major importance, since it influences the digestion of food and quality of life. There is a natural reduction in the secretion of gastric juice with aging, so the right preparation of the food bolus in mouth is essential. Thus, this step of the digestive process deserves special attention in edentulous patients due to limitations of conventional dentures, since the masticatory efficiency of CD wearers is only $16 \%$ to $50 \%$ that of dentate patients (1).

In the last years, the evidence-based dental practice has grown dramatically. This way, numerous clinical procedures became questionable in face of this new paradigm of clinical decision making. Several concepts that are routinely employed on the construction of CD are not based on strict scientific methods, but derives from clinical observation and repetition over the years, although it does not mean that they are incorrect (2). Traditional techniques have been used in CD construction without taking into account the needs and attitudes of individual patients (3). One of these concepts is the bilateral balanced occlusion (BBO), which is considered by many authors as fundamental for treatment success, as it would be able to provide greater retention and stability than the canine guidance (CG). Better masticatory function is attributed to the $\mathrm{BBO}$, since it brings more grinding surfaces in contact at each movement (4).

However, a critical review of the literature reveals that there is not sufficient scientific evidence to support $\mathrm{BBO}$ as the ideal occlusal concept (OC) for CD. Evidence suggests that the $\mathrm{OC}$ has little influence on clinical outcomes and patients' satisfaction $(5,6)$. Furthermore, procedures involved in the construction of a set of dentures with $\mathrm{BBO}$ are much more complex and

Correspondence: Dr. Arcelino Farias Neto, Departamento de Prótese e Periodontia, Faculdade de Odontologia de Piracicaba, Avenida Limeira, 901 Caixa Postal 52, 13414-903 Piracicaba, SP, Brasil. Tel/Fax: +55-19-2106-5295. e-mail: saudeoral@fop.unicamp.br 
time consuming than those for canine-guided dentures for both the dentist and the dental technician.

Further studies are necessary to investigate the advantages of BBO over CG. Thus, the aim of this study was to evaluate the masticatory efficiency of complete denture patients with $\mathrm{BBO}$ and $\mathrm{CG}$.

\section{MATERIAL AND METHODS}

A randomized crossover double-blinded clinical trial was conducted at the Department of Dentistry of the Federal University of Rio Grande do Norte, Brazil. The study was approved by the Research Ethics Committee of the institution (Protocol\# 001/08). Edentulous patients visiting the Clinic of Prosthodontics and requiring new conventional $\mathrm{CD}$ were invited to participate in this clinical trial. After a preliminary examination, patients were excluded if they exhibited symptoms of temporomandibular disorders, xerostomia, orofacial motor disorders, severe oral manifestations of systematic diseases or psychological or psychiatric conditions that could influence their response to treatment. The sample was composed by 24 patients with mean age of 59.7 years. All patients had previously worn CD. After giving informed consent, patients were randomized to one of the 2 treatment groups (BBO-CG or CG-BBO) with different treatment sequences. Three months after insertion of the new dentures, the occlusal concept was changed. Thus, patients were subjected to both occlusal concepts for the same period of 3 months. Data were collected by the masticatory efficiency test and questionnaires at 3 and 6 months after denture insertion by one examiner who was not informed about the occlusal concepts.

The dentures were fabricated in accordance with traditional techniques (7) and in cooperation with the undergraduate dental students. All dentures were fabricated with $\mathrm{BBO}$ by an experienced dental technician and checked clinically through visual analysis. Thus, the change from $\mathrm{BBO}$ to $\mathrm{CG}$ of all dentures was performed clinically by the same dentist by the addition of lightcured composite resin (Z100; 3M/ESPE, St. Paul, MN, USA) in the lower canines, in such a way that it could provide an interarch desocclusion space of $2 \mathrm{~mm}$ in the molar region during eccentric movements. In the CG-BBO, group this change was performed at the day of denture insertion, and in the BBO-CG group it was done after 3 months. To change from $\mathrm{CG}$ to $\mathrm{BBO}$, the composite resin was removed and the $\mathrm{BBO}$ occlusion reestablished. Always before data collection, the oc- clusal contacts were examined to verify whether they were in agreement with the occlusal concept proposed at that moment.

The technique applied to bond the composite to the acrylic resin teeth was the same described by Vergani et al. (8). Mechanical undercut holes were placed in the lower canines with an inverted cone carbide bur and the incisal surface of the teeth was treated with chloroform for $5 \mathrm{~s}$. Then, the teeth were rinsed with water for $20 \mathrm{~s}$. A thin layer of adhesive (Adper Scotchbond Multipurpose Plus; 3M/ESPE) was brushed into the mechanical undercut holes and over the incisal surfaces. The layer was cured for $20 \mathrm{~s}$ with a visible light source (Ultralux Eletronic; Dabi Atlante SA, Ribeirão Preto, SP, Brazil). The correct color of composite to match the artificial denture teeth was chosen. The composite resin (Z100; $3 \mathrm{M} / \mathrm{ESPE}$ ) was applied into the mechanical undercut holes and the resin was light cured for $40 \mathrm{~s}$. After resin polymerization, occlusal adjustment was done. Finally, the teeth were trimmed and polished with Soflex disks (3M/ESPE) and composite polishing paste (3M/ESPE).

Objective evaluation of masticatory function was performed through the colorimetric method. The beads were the artificial test-food used to measure masticatory efficiency (9). They were obtained by ionotropic jellification of an aqueous dispersion of $2 \%$ pectin containing $50 \%$ solids and fuchsin in a $1.0 \mathrm{M}$ calcium chloride solution. After preparation, the beads were coated with a 5\% Eudragite solution (Eudragit E100) in a solvent mixture of $10 \%$ acetone in absolute ethanol. Then, $250 \mathrm{mg}$ of the beads were packed in polyvinyl acetate capsules with $0.67 \mathrm{~mm}$ thick walls, inner diameter of $7.6 \mathrm{~mm}$ and outer diameter of $8.95 \mathrm{~mm}$, and sealed. The subjects were instructed to chew the beads in their habitual manner, seated on a chair with back and with both feet resting on the ground. The test stopped after $20 \mathrm{~s}$ and the beads were collected into a container identified by subject and test number. After mastication, the content of the capsule was dissolved in $5 \mathrm{~mL}$ of water by mixing constantly for $30 \mathrm{~s}$. The solution was then filtered through qualitative filter paper and the extracted dye was quantified in nanometers $(\mathrm{nm})$ with a Beckman DU-640 UV-Visible Spectrophotometer (Beckman Inc., Palo Alto, CA, USA). It allowed the measurement of masticatory efficiency on the basis of the concentration of extracted fuchsin, which was expressed in absorbance (abs). The analysis of the beads was carried out at the Biochemistry Laboratory of the Health Sciences Center, Federal University of Rio Grande do Norte, Brazil. 
A method for quantifying the overall satisfaction of CD wearers was used (10). Patients were asked to respond to questions with three-grade answers (well satisfied, satisfied, and dissatisfied) concerning 12 factors: chewing, tasting, speech, pain (upper and lower), esthetics, fit (upper and lower), retention (upper and lower) and comfort (upper and lower). Then, the three grades were turned into scores according to the degree of contribution of each factor as previously established. At the end of the study, patients were asked if they wanted to change the occlusal concept for the one of their choice.

The primary outcome measure selected for this evaluation was the masticatory efficiency. Absorbance values were compared between occlusal concepts using the Mann-Whitney test. Patient satisfaction was compared using the unpaired t-test and the relationship between masticatory efficiency and chewing rating was analyzed using the Kruskal-Wallis test. A significance level of $5 \%$ was set for all analyses.

\section{RESULTS}

One patient from the BBO-CG group and 2 patients from the CG-BBO left the study after 3 months and did not return for the 6-month appointment. At the end of the study, no patient asked for occlusal concept change. No statistically significant difference $(p=0.095)$ was found for masticatory efficiency (Table 1) between the two occlusal concepts studied, and no significant relationship $(\mathrm{p}=0.298)$ was found between masticatory efficiency and chewing rating either (Table 2 ). In addition, there was no significant difference $(\mathrm{p}=0.155)$ for patient overall satisfaction (Table 3).

\section{DISCUSSION}

The crossover design of this study is common on human research in Medicine and Dentistry and has been used in others trials that investigated OCs in complete dentures $(11,12)$. Its major advantage is the elimination of inter-subject response variation to the same treatment, since all treatments are applied to all subjects, increasing the statistical efficiency of the study given the need for a smaller number of subjects. A sample size of 24 patients was derived from a previously published crossover trial with similar purpose that had a sample size of 20 subjects (12). Furthermore, since each patient works as his/her own control, the crossover design allows the reduction of the effect of non-controlled external variables, such as sex, previous denture experience, mucosal health status and resiliency, and alveolar ridge height and width. On the other hand, a problem with crossover trials is the carry-over effect. While a washout period is necessary in pharmacological trials, carry-over effects are unlikely in oral rehabilitation. Therefore, a washout period was not included. Additionally, leaving patients without a denture for a washout period was not considered possible for ethical reasons (12). Then, two different treatment sequences were used to avoid bias.

Unlike previous studies that investigated masticatory function in complete dentures (11-13), this clinical trial measured the masticatory efficiency with the beads. In this method, the test material is promptly evaluated and has stable physical properties. Since the beads are packed in the capsules, the material is fully obtained

Table 1. Data for masticatory efficiency.

\begin{tabular}{lcccc}
\hline $\begin{array}{l}\text { Occlusal } \\
\text { concept }\end{array}$ & $\mathrm{N}$ & $\begin{array}{c}\text { Mean } \\
(\mathrm{abs})\end{array}$ & $\begin{array}{c}\text { Standard } \\
\text { deviation }\end{array}$ & Range \\
\hline $\begin{array}{l}\text { Bilateral } \\
\text { balanced } \\
\text { occlusion }\end{array}$ & 22 & 0.186 & 0.041 & $0.168-0.205$ \\
$\begin{array}{l}\text { Canine } \\
\text { guidance }\end{array}$ & 23 & 0.167 & 0.016 & $0.160-0.174$ \\
\hline
\end{tabular}

Abs $=$ absorbance.

Table 2. Data for masticatory efficiency according to chewing rating.

\begin{tabular}{lcccc}
\hline $\begin{array}{l}\text { Masticatory } \\
\text { ability }\end{array}$ & $\mathrm{N}$ & $\begin{array}{c}\text { Mean } \\
(\mathrm{abs})\end{array}$ & $\begin{array}{c}\text { Standard } \\
\text { deviation }\end{array}$ & Range \\
\hline Dissatisfied & 6 & 0.167 & 0.017 & $0.149-0.185$ \\
Satisfied & 22 & 0.180 & 0.034 & $0.165-0.195$ \\
Well satisfied & 17 & 0.174 & 0.033 & $0.157-0.191$ \\
\hline
\end{tabular}

Abs $=$ absorbance.

Table 3. Data for patient satisfaction.

\begin{tabular}{lcccc}
\hline $\begin{array}{l}\text { Occlusal } \\
\text { concept }\end{array}$ & $\mathrm{N}$ & Mean & $\begin{array}{l}\text { Standard } \\
\text { deviation }\end{array}$ & Range \\
\hline $\begin{array}{l}\text { Bilateral } \\
\text { balanced } \\
\text { occlusion }\end{array}$ & 22 & 87.2 & 7.9 & $83.7-90.7$ \\
$\begin{array}{l}\text { Canine } \\
\text { guidance }\end{array}$ & 23 & 90.2 & 5.8 & $87.7-92.7$ \\
\hline
\end{tabular}


from the mouth, with no danger of being swallowed nor dissolved by saliva. Laboratory processing is fast and effective and allows determining exactly the patient's masticatory efficiency. The capsules are not torn nor ripped during mastication, and thus the granules are kept inside the capsule. All granule components are listed in the Brazilian pharmacopoeia and can be reproduced (9).

Two occlusal concepts exist in CD treatment: $\mathrm{BBO}$ and $\mathrm{CG}$. Both include simultaneous contact in centric occlusion, but they differ in eccentric movements. The fact that $\mathrm{OC}$ is the most appropriated for individuals' needs is clinically and economically relevant. Procedures involved in the construction of a set of dentures with BBO are much more complex and time-consuming than those for canine-guided dentures for dentist and dental technician. It is more complicated to achieve BBO during the arrangement of prosthetic teeth and clinical adjustments. Furthermore, studies suggest that the occlusal concept has little influence on clinical outcomes and patients' satisfaction $(5,6)$. There is only a weak relationship between patients' satisfaction and clinical variables considered relevant for successful treatment $(14,15)$. Thus, it is reasonable to use technical procedures that produce acceptable clinical results in a minimum amount of time and effort.

Masticatory efficiency is defined as the capacity to reduce food during mastication (16). The results of this study showed no significant difference for the masticatory efficiency between the occlusal concepts proposed. These results were similar to those found in other investigations $(13,17)$ and are in contrast with the opinion that the BBO promotes better masticatory efficiency by bringing a larger amount of grinding surfaces into contact at each movement (4). Furthermore, no significant difference for patient satisfaction was found in this study although recent clinical trials have found more preference for CG $(11,12)$.

Masticatory ability is the individual's own assessment of his or her masticatory function (16). The relationship between masticatory efficiency and the subjective chewing experience is weak or absent (18). Thus, masticatory function must be evaluated in both manners, especially in edentulous patients, because the psychological aspect is fundamental for the successful rehabilitation with CD (19). In this study, no relationship between masticatory efficiency and chewing rating was found. Besides, there was no significant difference for patient overall satisfaction. Therefore, the CG seems to be a viable approach because it is easier to be achieved by dentists and dental technicians and does not compromise function and satisfaction.

Proponents of BBO believe that this OC is important for denture retention and stability (4). In the present study, dentures with CG were expected to impair masticatory function because the highest incidence of oblique forces capable of dislodging the denture and thus causing traumatic ulcers on oral mucosa during mastication. However, it did not happen. Thus, it is supposed that $C G$ does not decrease retention and stability. Balancing contacts are not found during mastication and probably are not physiologically necessary. With the food bolus between the teeth, the occlusal surfaces do not make contact with each other, but with the food.

Some authors argue that BBO centralizes forces on the residual alveolar ridges to protect alveolar bone from resorption (20), but there is not any study that has investigated this variable. To evaluate the effect of occlusal concepts on bone resorption long-term controlled clinical trials are necessary, although it is difficult to be accomplished due to many variables involved and the age of patients. The explanation for protection against bone resorption is that $\mathrm{BBO}$ promotes symmetrical distribution of stress on the alveolar ridges. However, as during mastication there is no balancing contact, there is no distribution of forces on both sides of the arches as well. To avoid all of these problems in denture retention, stability and bone resorption, it seems to be more reasonable to instruct the patient not to incise, but rather put small pieces of food in the mouth and masticate on both sides of the arch.

Therefore, there is no clinical evidence to support $\mathrm{BBO}$ as the ideal $\mathrm{OC}$ for $\mathrm{CD}$ wearers. As $\mathrm{CG}$ is easier and faster to be provided, it seems to be rational to recommend this occlusal concept for the excursive movements of the mandible in complete dentures wearers until future research can solve this question. Additional randomized controlled clinical trials should be developed taking into account the influence of gender, mucosal resiliency and alveolar ridge height on masticatory efficiency and its importance on OC choice.

Based on the results, it may be concluded that bilateral balanced occlusion does not improve masticatory efficiency in complete denture wearers.

\section{RESUMO}

A manutenção da função mastigatória tem importância especial em pacientes portadores de prótese total devido às limitações inerentes a esse tipo de prótese. Nesse contexto, a oclusão bal- 
anceada bilateral (OBB) é empregada com o intuito de obter-se uma maior eficiência mastigatória. Entretanto, analisando-se a literatura criticamente, observa-se que não existem evidências científicas suficientes que suportem a aplicação da OBB como conceito oclusal ideal em prótese total (PT). Assim, o presente trabalho teve o objetivo de verificar se pacientes portadores de PT dupla com OBB apresentam maior eficiência e capacidade mastigatória que aqueles com desoclusão com guia canino (DGC). Com esse intuito, realizou-se um ensaio clínico controlado duplocego do tipo crossover. A amostra foi composta de 24 pacientes portadores de prótese total dupla, onde todos fizeram uso de ambos os conceitos oclusais por períodos iguais de 3 meses. A avaliação da eficiência mastigatória foi realizada através do método colorimétrico com o uso de cápsulas mastigatórias. Não se encontrou diferença estatística significativa para a eficiência $(p=0,0952)$ entre os dois conceitos oclusais estudados. Dessa forma, pode-se concluir que usuários de PT dupla com OBB não apresentam maior eficiência mastigatória que aqueles com DGC.

\section{REFERENCES}

1. Heath MR. The effect of maximum biting force and bone loss upon masticatory function and dietary selection of the elderly. Int Dent J 1982;32:345-356.

2. Carlsson GE. Facts and fallacies: an evidence base for complete dentures. Dent Update 2006;33:134-142.

3. Ellis JS, Pelekis ND, Thomason JM. Conventional rehabilitation of edentulous patients: the impact on oral health-related quality of life and patient satisfaction. J Prosthodont 2007;16:37-42.

4. Zarb GA, Bolender CL, Eckert SE, Fenton AH, Jacob RF, Mericske-Stern R. Prosthodontic treatment for edentulous patients - complete dentures and implant-supported prostheses. St. Louis: Mosby; 2003.

5. Palla $\mathrm{S}$. The interface of occlusion as a reflection of conflicts within prosthodontics. Int J Prosthodont 2005;18:304-306.

6. Sutton AF, Glenny AM, McCord JF. Interventions for replacing missing teeth: denture chewing surface designs in edentulous people Cochrane Database Syst Rev 2005;25:CD004941.

7. Kawai Y, Murakami H, Shariati B, Klemetti E, Blomfield JV, Billette $\mathrm{L}$ et al.. Do traditional techniques produce better conventional complete dentures than simplified techniques? J Dent
2005;33:659-668.

8. Vergani CE, Giampaolo ET, Cucci AL. Composite occlusal surfaces for acrylic resin denture teeth. J Prosthet Dent 1997;77:328331.

9. Escudeiro Santos C, Freitas O, Spadaro ACC, Mestriner-Junior W. Development of a colorimetric system for evaluation of the masticatory efficiency. Braz Dent J 2006;17:95-99.

10. Sato Y, Hamada S, Akagawa Y, Tsuga K. A method for quantifying overall satisfaction of complete denture patients. J Oral Rehabil 2000;27:952-957.

11. Peroz I, Leuenberg A, Haustein I, Lange KP. Comparison between balanced occlusion and canine guidance in complete denture wearers - a clinical, randomized trial. Quintessence Int 2003;34:607612.

12. Heydecke G, Akkad AS, Wolkewitz M, Vogeler M, Türp JC, Strub JR. Patient ratings of chewing ability from a randomised crossover trial: lingualised vs. first premolar/canine-guided occlusion for complete dentures. Gerodontology 2007;24;77-86.

13. Motwani BK, Sidhaye AB. The need of eccentric balance during mastication. J Prosthet Dent 1990;64:689-690.

14. de Baas C, van Aken AMA, Mulder J, Kalk W. "Prosthetic condition" and patients' judgment of complete dentures. J Prosthet Dent 1997; 78:472-478.

15. Heydecke G, Klemetti E, Awad MA, Lund JP, Feine JS. Relationship between prosthodontic evaluation and patient ratings of mandibular conventional and implant prostheses. Int J Prosthodont 2003;16:307-312.

16. Carlsson GE. Masticatory efficiency: the effect of age, the loss of teeth and prosthetic rehabilitation. Int Dental J 1984;34:93-96.

17. Trapozzano VR. Tests of balanced and nonbalanced occlusions. J Prosthet Dent 1960;10:476-487.

18. Slagter AP, Olthoff LW, Bosman F, Steen WH. Masticatory ability, denture quality, and oral conditions in edentulous subjects. J Prosthet Dent 1992;68:299-307.

19. Boretti G, Bickel M, Geering AH. A review of masticatory ability and efficiency. J Prosthet Dent 1995;74:400-403.

20. Pound E. Lost-fine arts in the fallacy of the ridges. J Prosthet Dent 1954;4:6-16.

Accepted April 20, 2010 